\title{
Dampak Pertobatan Orang Percaya Ditinjau Dari Perspektif Teori Belajar Behavioristik Ivan Petrovich Pavlov Berdasarkan Kisah Para Rasul 2:41-47
}

\author{
Feby Bunga Parri, Julianus Buyi, Leoni Wenifred, Nicolas Irang \\ parrifebybunga@gmail.com julianusbuyi16@gmail.com wenifredleoni05@gmail.com \\ nicolasirang69@gmail.com \\ Sekolah Tinggi Filsafat Theologia Jaffray Makassar
}

\begin{abstract}
Abstrak
Gaya hidup yang bertobat ini merupakan tindakan secara sadar bahwa perilaku di masa lalu adalah salah, dan ingin merubah itu menjadi perilaku yang serupa dengan karakter Kristus. Ini adalah sebua proses belajar bagi orang percaya yang terjadi secara terusmenerus di dalam kehidupannya. Proses pembelajaran ini sesuai jika ditinjau dari perspektif teori belajar Behavioristik, secara khusus teori yang dikembangkan oleh Ivan Petrovich Pavlov. Tujuan akhir dari pembelajaran ini adalah kesadaran otomatis akan gaya hidup bertobat, yang akhirnya menjadi suatu kebiasaan. Kebiasaan hidup yang bertobat inilah yang akan menghasilkan dampak, yaitu perubahan-perubahan perilaku hidup yang secara otomatis akan terjadi dengan bantuan Roh Kudus seperti yang terjadi pada cara hidup jemaat mula-mula dalam Kisah Para Rasul 2:41-47. Gaya hidup bertobat harus diajarkan melalui pengajaran-pengajaran yang berdasarkan Alkitab sebagai inpuls, sehingga dapat menghasilkan output berupa respon, yaitu gaya hidup yang bertobat. Berdasarkan latar belakang di atas maka penulis menetapkan tujuan penulisan, yaitu untuk menganalisa dampak pertobatan orang percaya yang ditinjau dari perspektif teori belajar Behavioristik Ivan Petrovich Pavlov berdasarkan Ksiah Para Rasul 2:41-47. Adapun metode yang digunakan adalah metode eksposisi Alkitab, yaitu eksposisi Kisah Para Rasul 2:41-47. Eksposisi Alkitab ini adalah uraian (paparan) yang bertujuan menjelaskan maksud dan tujuan dari pokok yang dibahas dan metode selanjutnya adalah penelitian literature (kepustakaan), yaitu mengumpulkan data dari buku-buku dan sumber lain yang membahas tentang pertobatan dan teori belajar Behavioristik Ivan Petrovich Pavlov.
\end{abstract}

Kat -kata kunci: pertobatan, Behavioristik, Ivan Pavlov. Kisah Para Rasul 


\section{PENDAHULUAN}

Keselamatan merupakan hasil dari apa yang Yesus kerjakan, aspek keselamatan mencangkup banyak hal dan juga memiliki arti dalam cakupan hidupan manusia di masa depan. Namun sasaran utama dalam pembahasan jurnal ini, adalah membahas tanggapan manusia khususnya orang Kristen terhadap apa yang telah Allah buat baginya. Setiap orang yang menyerahkan dirinya bagi Yesus harus benar-benar meninggalkan kehidupan lamanya, atau di dalam istilah teologis mengalami pertobatan. Pertobatan merupakan langkah awal di dalam kekristenan setelah itu diikuti oleh iman dan pengampunan. Namun penulis menaruh perhatian khusus kepada langkah awal kehidupan Kristen, yaitu membawa orang ke dalam pengalaman kristiani.

Tetapi bagaimana jika pertobatan hanya sekedar sebuah pengalaman baru bagi orang percaya, dan hanya menjadi sebuah istilah atau ritual dalam kehidupan orang percaya yang baru menyerahkan dirinya untuk mengenal Kristus? Kasus seperti ini sering terjadi di dalam kehidupan orang percaya. Banyak orang percaya yang memiliki pemahaman bahwa pertobatan terjadi ketika mereka melakukan baptisan, sebagian lagi berpikir bahwa jalan keselamatan diperoleh ketika mereka dibaptis dan menerima Yesus sebagai Tuhan dan Jurusselamat. Hal ini menyebabkan masalah baru dalam kehidupan Kekristenan, menyepelekan akan hal ini menghasilkan masalah yang serius. Orang percaya hidup sesuai dengan apa yang dia inginkan, tanpa menghargai apa yang diperoleh secara cuma-cuma dan menganggap pertobatan hanya sekedar pengalaman dan istilah yang dianut sebagai orang Kristen.

Pertobatan juga bukan hanya berbicara tentang kegiatan kerohanian saja, karena pemahaman yang salah sering juga terjadi dalam jemaat yang sudah dibaptis dan melakukan hal-hal yang bersifat rohani hanya sebagai kewajiban saja, dalam hal ini perlu ada pendewasaan, atau kedewasaan rohani bagi orang-orang yang baru bertobat atau lahir baru. Dalam 1 Pet 2:2 orang yang baru bertobat bisa dikatakan seorang bayi yang belum dewasa secara rohani dan memerlukan bimbingan agar bertumbuh dan beroleh keselamatan. Oleh sebab itu penting bagi orang percaya untuk memiliki gaya hidup yang bertobat. Yang dimaksud gaya hidup bertobat dilakukan dengan pertobatan yang dilakukan setiap hari, hal ini dilakukan dengan penuh kesadaran bahwa ia adalah orang berdosa yang setiap hari memerlukan pembaharuan dari Roh Kudus.

Gaya hidup yang bertobat ini merupakan tindakan secara sadar bahwa perilaku di masa lalu adalah salah, dan ingin merubah itu menjadi perilaku yang serupa dengan karakter Kristus. Ini adalah sebua proses belajar bagi orang percaya yang terjadi secara terus-menerus di dalam kehidupannya. Proses pembelajaran ini sesuai jika ditinjau dari perspektif teori belajar Behavioristik, secara khusus teori yang dikembangkan oleh Ivan Petrovich Pavlov. Tujuan akhir dari pembelajaran ini adalah kesadaran otomatis akan gaya hidup bertobat, yang akhirnya menjadi suatu kebiasaan. Kebiasaan hidup yang bertobat inilah yang akan menghasilkan dampak, yaitu perubahan-perubahan perilaku hidup yang secara otomatis akan terjadi dengan bantuan Roh Kudus seperti yang terjadi pada cara hidup jemaat mula-mula dalam Kisah Para Rasul 2:41-47. Gaya hidup bertobat harus diajarkan melalui pengajaran-pengajaran yang berdasarkan Alkitab sebagai inpuls, sehingga dapat menghasilkan output berupa respon, yaitu gaya hidup yang bertobat. 
Berdasarkan latar belakang di atas maka penulis menetapkan tujuan penulisan, yaitu untuk menganalisa dampak pertobatan orang percaya yang ditinjau dari perspektif teori belajar Behavioristik Ivan Petrovich Pavlov berdasarkan Ksiah Para Rasul 2:41-47. Adapun metode yang digunakan adalah metode eksposisi Alkitab, yaitu eksposisi Kisah Para Rasul 2:41-47. Eksposisi Alkitab ini adalah uraian (paparan) yang bertujuan menjelaskan maksud dan tujuan dari pokok yang dibahas dan metode selanjutnya adalah penelitian literature (kepustakaan), yaitu mengumpulkan data dari buku-buku dan sumber lain yang membahas tentang pertobatan dan teori belajar Behavioristik Ivan Petrovich Pavlov. 


\section{KAJIAN TEORI}

\section{A. Teori Belajar Behavioristik Ivan Petrovich Pavlov}

Pendidikan merupakan bimbingan atau pertolongan yang diberikan atau disampaikan oleh seorang guru kepada perkembangan orang yang diajarnya atau siswa untuk mencapai kedewasaan dengan tujuan agar siswa cukup cakap melaksanakan tugas hidupnya sendiri tidak dengan bantuan orang lain. ${ }^{1}$

Pendidikan adalah kebutuhan yang utama pada era ini, pendidikan sangat diperlukan oleh setiap orang. Selain pendapat di atas tujuan setiap orang menempuh pendidikan adalah untuk mengembangkan potensi agar menjadi manusia yang beriman dan bertakwa kepada Tuhan Yang Maha Esa, berahlak mulia, sehat, berilmu, cakap, kreatif, mandiri, dan menjadi warga Negara yang demokratis serta bertanggung jawab. ${ }^{2}$ Dalam proses pendidikan selalu terjadi proses pembelajaran, proses pembelajaran terjadi saat guru menjadi pengajar dan siswa menjalani proses belajar. Belajar merupakan suatu aktivitas mental atau psikis yang dilakukan oleh seseorang dan terjadi karena interaksi dengan lingkungan yang menghasilkan perubahan dalam pengetahuan, pemahaman, keterampilan dan nilai sikap. ${ }^{3}$

Dalam perkembangan proses pendidikan ahli-ahli menemukan berbagai teori yang dapat dilakukan dalam pembelajaran. Teori belajar merupakan seperangkat pernyataan umum yang digunakan untuk menjelaskan kenyataan mengenai belajar. ${ }^{4}$ Selain itu, teori belajar juga merupakan gabungan prinsip yang saling berhubungan dan penjelasan atas sejumlah fakta serta penemuan yang berkaitan dengan peristiwa belajar. ${ }^{5}$ Pada dasarnya teori belajar terdiri dari dua macam teteori, yaitu teori Asosiasi yang berorientasi induktif dan teori lapangan (field theory). ${ }^{6}$ Salah satu teori Asosiasi adalah Teori belajar Behavioristik.

Teori belajar behavioristik merupakan teori yang didasarkan perubahan tingkah laku, dan perubahan ini adalah perubahan yang dapat diamati. Behaviorisme berfokus pada penempatan diri dalam sebuah pola perilaku baru yang diulangi sampai prilaku tersebut menjadi kebiasaan. Kajian perlilaku teori ini terkonsenterasi pada perilaku nyata yang dapat diukur. Respon terhadap stimulus dapat diamati secara kuantitatif, apa yang ada dalam pikiran menjadi diabaikan karena proses pemikiran tidak bisa diamati secara jelas perubahan prilakunya. ${ }^{7}$ Teori belajar ini berfokus pada prilaku nyata dan tidak terkait dengan hubungan kesadaran atau konstruksi mental. Ciri utama teori belajar behavioristik adalah guru bersikap otoriter dan sebagai agen induktrinasi dan

\footnotetext{
${ }^{1}$ Reia Litalisdiana, "PENERAPAN TEORI BEHAVIORISME DALAM PENDIDIKAN DASAR KELAS II SDN PANGGANG” (n.d.): 1.

${ }^{2}$ Ayi Suherman, "MODEL PEMBELAJARAN PAKEM DALAM PENDIDIKAN JASMANI DI SEKOLAH DASAR,” Jurnal Penelitian Pendidikan Vol. 11, No. 1 (April 2010): 132.

${ }^{3}$ Zulhammi, "Teori Belajar Behavioristik Dan Humanistik Berdasarkan Perspekti f Pendidikan Islam,” Jurnal Darul Ilmi Vol. 3, No. 1 (January 2015): 105.

${ }^{4}$ MUHAMMAD IMAM BUSTANUL Arifin, "PENGARUH PENERAPAN TEORI BELAJAR BEHAVIORISTIK DAN PRINSIP-PRINSIP PEMBELAJARAN TERHADAP MOTIVASI BELAJAR PESERTA DIDIK SMP AL-ISLAM GUNUNGPATI SEMARANG”(October 16, 2016): 38.

${ }^{5}$ Novi Irwan Nahar, "PENERAPAN TEORI BELAJAR BEHAVIORISTIK DALAM PROSES PEMBELAJARAN," Nusantara ( Jurnal Ilmu Pengetahuan Sosial ) Volume 1 (December 2016): 65.

${ }^{6}$ Familus, "TEORI BELAJAR ALIRAN BEHAVIORISTIK SERTA IMPLIKASINYA DALAM PEMBELAJARAN," Jurnal PPKn \& Hukum Vol. 11, No. 2 (October 2016): 98.

${ }^{7}$ Deni Hardianto, Deni, and Hardianto, "PARADIGMA TEORI BEHAVIORISTIK DALAM PENGEMBANGAN MULTIMEDIA PEMBELAJARAN” (n.d.): 3.
} 
propaganda dan sebagai pengendali masukan prilaku. ${ }^{8}$ Dalam teori belajar ini seseorang telah dianggap belajar apabila mampu menunjukkan perubahan tingkah laku. ${ }^{9}$ Upaya pembentukan tingkah laku individu dikendalikan oleh penguatan (reinforcement) berupa hadiah (reward) maupun hukuman (punisment) dari lingkungan yang menjadi salah satu komponen dari teori behavioristik. ${ }^{10}$ Adapun tokoh-tokoh utama yang berperan dalam proses perkembangan teori belajar ini antara lain, Ivan Pavlov, Watson, Throndike, dan B.F Skinner. ${ }^{11}$

Salah satu tokoh yang terkenal adalah teori yang dikembangkan oleh Ivan Pavlov, yang lebih banyak dikenal dengan bunyi bel. Hal ini dikarenakan Pavlov melakukan eksperimen dengan melibatkan makanan, anjing dan bel. Pavlov dikenal dengan karyanya tentang pengkondisian klasik atau substitusi stimulus. ${ }^{12}$ Dalam eksperimennya dia melihat bahwa subjek penelitiannya (seekor anjing) akan mengeluarkan air liur sebagai respons atas munculnya makanan. Dia kemudian mengeksplorasi fenomena ini dan kemudian mengembangkan satu studi perilaku (behavioral study) yang dikondisikan, yang dikenal dengan teori Classical Conditioning. Menurut teori ini, ketika makanan (makanan disebut sebagai the unconditioned or unlearned stimulus - stimulus yang tidak dikondisikan atau tidak dipelajari) dipasangkan atau diikutsertakan dengan bunyi bel (bunyi bel disebut sebagai the conditioned or learned stimulus - stimulus yang dikondisikan atau dipelajari), maka bunyi bel akan menghasilkan respons yang sama, yaitu keluarnya air liur dari si anjing percobaan. ${ }^{13}$

Teori Belajar Behavioristik yang dikembangkan oleh Ivan Petrovich Pavlov menyatakan bahwa, setiap manusia membutuhkan perubahan dan akan mengalami perubahan dalam perilakunya sebagai hasil interaksi antara stimulus dan responden. ${ }^{14}$ Belajar adalah perubahan, perubahan yang dialami oleh klien atau siswa dalam mengembangkan mereka. ${ }^{15}$

Proses pembelajaran mengunakan teori belajar ini dapat mengubah perilaku klien atau pelajar menjadi seperti yang guru harapkan. ${ }^{16}$ Hal ini terjadi karena perilaku

\footnotetext{
${ }^{8}$ Nahar, "PENERAPAN TEORI BELAJAR BEHAVIORISTIK DALAM PROSES

PEMBELAJARAN," 65.

${ }^{9}$ Litalisdiana, "PENERAPAN TEORI BEHAVIORISME DALAM PENDIDIKAN DASAR KELAS II SDN PANGGANG,” 1.

${ }^{10}$ Bariyah Oktariska and Anselmus J.E Toenlioe, "STUDI KASUS PENERAPAN TEORI BELAJAR BEHAVIORISTIK DALAM MENUMBUHKEMBANGKAN PERILAKU PEDULI LINGKUNGAN HIDUP SISWA DI SMKN 6 MALANG Bariyah Oktariska, Anselmus J.E Toenlioe, Susilaningsih," JKTP Volume 1, Nomor 2 (June 2018): 160.

${ }^{11}$ Deni Hardianto, Deni, and Hardianto, "PARADIGMA TEORI BEHAVIORISTIK DALAM PENGEMBANGAN MULTIMEDIA PEMBELAJARAN," 3.

12 Ibid.

13 Titin Nurhidayati, "IMPLEMENTASI TEORI BELAJAR IVAN PETROVICH PAVLOV (CLASSICAL CONDITIONING ) DALAM PENDIDIKAN," JURNAL FALASIFA Vol. 3, No. 1 (March 2012): 23

${ }^{14}$ Ni Luh Linda Seniasih, Suranata K, and Ketut Darsana, "Effectiveness Behavioral Counseling Ivan Pavlov Modeling Techniques on Lesson Study Setting to Improve Allied Characters," Global Conferences Series: Sciences and Technology (GCSST 1 (2019): 171.

${ }^{15}$ Karmila Jayanthi, Ketut Dharsana, and Dantes Nyoman, “Ivan Pavlov’s Behavioral Counseling Effectiveness With Modeling Techniques to Improve Character Speaks Funnyly, Through Lesson Study," Global Conferences Series: Sciences and Technology (GCSST) Volume 1 (2019): 73.

${ }^{16}$ I Komang Ribek Budiarta Teja, Ketut Darsana, and K Sunarta, "Effectiveness of Behavioral Ivan Pavlov Conservation with Modeling Techniques to Increase Characters Helps Others Through Lesson Study," Global Conferences Series: Sciences and Technology (GCSST) Volume 1 (2019): 161.
} 
manusia pada dasarnya dibentuk dan ditentukan oleh lingkungan, dan semua perilaku dipelajari atau diperoleh dalam proses pelatihan. ${ }^{17}$ Pavlov menjelaskan belajar merupakan sebuah proses perubahan yang terjadi disebabkan adanya syarat-syarat atau conditions, yang dapat berbentuk latihan yang dilakukan secara kontinuitas atau terus menerus sehingga menimbulkan reasksi (response). Kelemahan teori ini adalah menganggap bahwa belajar adalah hanyalah terjadi secara otomatis dan lebih menonjolkan peranan latihan-latihan, dimana keaktifan dan pribadi seseorang tidak dihiraukan. ${ }^{18}$

\section{Kisah Para Rasul 2:41-47}

Perikop Kisah Para Rasul 2:41-47 tersebut merupakan satu kesatuan unit yang ditandai dengan adanya inklusio, yaitu ayat 41 dan $47 \mathrm{~b}$, yang dalam kedua ayat pembuka dan penutup tersebut sama- sama mengetengahkan penambahan jumlah jiwa setelah peristiwa Pentakosta di Yerusalem. ${ }^{19}$ Ayat 41 mencatat mengenai khotbah Petrus kepada jemaat yang berada di Yerusalem. Ketika Petrus selesai menyampaikan khotbanya, Petrus menyerukan kepada jemaat untuk memberikan dirinya dibaptis. Bentuk penyerahan diri yang dilakukan dalam bentuk tanda baptisan, merupakan pengalaman pertama seorang kristiani di dalam pertobatan. Hal ini sama seperti yang dilakukan Yesus setiap kali memanggil orang banyak untuk bertobat. Bagi Yesus pertobatan adalah suatu perubahan kearah yang radikal, bukan hanya saja sekedar perubahan dalam tingkah laku, tetapi juga perubahan yang meliputi pikiran yang juga mengubah perspektif jemaat tentang Tuhan, yakni bahwa Yesus Kristus merupakan satu-satunya jalan keselamatan.

Ayat 42- 47 menjelaskan apa yang dialami para petobat setelah menjadi orang Kristen. Pertobatan massal saja tidak cukup kegiatan kesaharian saja tidak memadai, kekristenan tidak boleh berpatokan pada pertemuan akbar kebaktian rohani saja. Kerohanian yang sudah dibangun haruslah dipelihara seperti yang dilakukan oleh jemaat mula-mula. ${ }^{20}$

Adapun ciri jemaat yang mula-mula yang memelihara kerohanian mereka berdasarkan perikop ini, yaitu:

1. Berakar di dalam Firman. Tekun dan hidup di dalam pengajaran firman Tuhan adalah salah satu kekuatan utama di dalam kehidupan rohani jemaat mula-mula. Mereka menaklukan diri dan mengikuti secara konsisten semua hal baru yang diajarkan para rasul di Yerusalem. Kelompok ini berakar di dalam firman karena mereka mau dididik dan diajar dengan kebenaran (punya teachable spirit). ${ }^{21}$

\footnotetext{
${ }^{17}$ Dimas Azhar, Kadek Suranata, and I Ketut Darsana, "Implementation of The Behavioral Ivan Pavlov Conservation Theory with Modeling Techniques on Lesson Study Setting to Improve Self Achievement Students of The XI Class of Ibb SMA Lab Undiksha," Global Conferences Series: Sciences and Technology (GCSST) Volume 1 (2019): 157.

${ }^{18}$ Litalisdiana, "PENERAPAN TEORI BEHAVIORISME DALAM PENDIDIKAN DASAR KELAS II SDN PANGGANG," 4.

${ }^{19}$ Yushak Soesilo, "Pentakostalisme Dan Aksi Sosial: Analisis Struktural Kisah Para Rasul 2:4147,” Jurnal Teologi dan Pendidikan Kristiani Volume 2, Nomor 2 (April 2018): 139.

${ }^{20}$ Daniel Sutoyo, "Gaya Hidup Jemaat Mula-Mula Yang Disukai Berdasarkan Kisah Para Rasul 2:41-42 Bagi Gereja Masa Kini” (n.d.): 29.

${ }^{21}$ Sonny Eli Zaluchu, "Eksegesis Kisah Para Rasul 2:42-47 Untuk Merumuskan Ciri Kehidupan Rohani Jemaat Mula-Mula Di Yerusalem," Jurnal Teologi dan Pelayanan Kristiani Vol 2, No. 2 (November 2018): 78.
} 
2. Hidup di dalam Persekutuan Menurut definisi Morley, persekutuan adalah semua unsur yang didalamnya terdapat persahabatan, kemitraan, perasaan senasib, hubungan yang membangun dan menguatkan, persaudaraan serta tinggal dan berkumpul. $^{22}$

3. Memiliki Gaya Hidup Doa Bertekun di dalam doa adalah salah satu gaya hidup rohani yang diperlihatkan secara radikal oleh jemaat mula-mula. Mereka mengadakan pertemuan bukan sematamata untuk tujuan beribadah dan berinteraksi satu sama lain, tetapi mereka berdoa secara korporat di dalam setiap pertemuan itu. Selalu berkumpul untuk berdoa, sebagaimana dituliskan Lukas, adalah penekanan bahwa doa menjadi bagian dari gaya hidup keseharian mereka. Jemaat mula-mula menyadari bahwa doa membawa kesadaran akan adanya Allah dan kebergantungan kepadaNya. Sebagaimana dikatakan Morley, doa menjadi kesempatan untuk mengadakan persekutuan dengan Bapa di surge. ${ }^{23}$

4. Peduli terhadap Sesama Salah satu bentuk kepedulian di dalam komunitas jemaat mula-mula adalah sikap berbagi dan rela berkorban.Mereka peduli terhadap kebutuhan material orang lain dan siap menjual harta pribadi untuk pemenuhan kebutuhan primer tersebut. Prinsip yang ditekankan adalah kepemilikan bersama (saling memiliki). ${ }^{24}$

\section{Hubungan Nast dengan teori yang digunakan}

Gaya hidup yang bertobat ini merupakan tindakan secara sadar bahwa perilaku di masa lalu adalah salah, dan ingin merubah itu menjadi perilaku yang serupa dengan karakter Kristus. Ini adalah sebua proses belajar bagi orang percaya yang terjadi secara terus-menerus di dalam kehidupannya. Proses pembelajaran ini sesuai jika ditinjau dari perspektif teori belajar Behavioristik, secara khusus teori yang dikembangkan oleh Ivan Petrovich Pavlov. Tujuan akhir dari pembelajaran ini adalah kesadaran otomatis akan gaya hidup bertobat, yang akhirnya menjadi suatu kebiasaan.

Kebiasaan hidup yang bertobat inilah yang akan menghasilkan dampak, yaitu perubahan-perubahan perilaku hidup yang secara otomatis akan terjadi dengan bantuan Roh Kudus seperti yang terjadi pada cara hidup jemaat mula-mula dalam Kisah Para Rasul 2:41-47. Gaya hidup bertobat harus diajarkan melalui pengajaran-pengajaran yang berdasarkan Alkitab sebagai inpuls, sehingga dapat menghasilkan output berupa respon, yaitu gaya hidup yang bertobat. Ini sesuai dengan teori belajar Behavioristik seperti yang dikembangkan oleh Ivan Pavlov.

\footnotetext{
22 Ibid., 79.

${ }^{23}$ Ibid., 80.

${ }^{24}$ Ibid., 81.
} 


\section{METODE}

Metode penulisan makalah ini adalah analisis data kualitatif yaitu menjelaskan data-data yang dikumpulkan sesuai dengan teori-teori yang dirangkum dari hasil penelitian. ${ }^{25}$ Selanjutnya dengan menggunakan model pembelajaran kooperatif berbasis media sosial. ${ }^{26}$ Dengan menggunakan metode 5P (Belajar berarti berubah). ${ }^{27}$

Metode yang digunakan dalam proses pembelajaran ini adalah metode belajar 5P, yaitu Penghubung, pelajaran, penerapan, perubahan, dan penutupan. Berikut langkah dalam mengajar yang dilakukan oleh penulis:

\section{Memberi Diri Untuk Berubah}

Fokus: Bagaiamana peserta kegiatan belajar dapat berpikir, bersikap, dan bertindak setelah mengalami sendiri Firman Tuhan tersebut.

1. Penghubung: Pertemuan yang mengubahkan

(Semua peserta didik membentuk kelompok-kelompok yang menyerupai jemaat yang sedang diajar oleh rasul-rasul)

Semua peserta mengambil peran dalam cerita tersebut. Narator akan membacakan ayat firman Tuhan dari Kisah Para Rasul 2:41-47. Selama mendengar cerita, pikirkan, rasakan, dan lakukan bagian firman Tuhan tersebut. 3 Sukarelawan akan berperan sebagai rasul-rasul (salah satunya adalah Petrus) dan dan sisanya akan menjadi orangorang percaya.

Silahkan dengarkan firman Tuhan sebagai petunjuk drama.

Marilah kembali ke tempat duduk masing-masing.

Ceritakanlah: bagaimana perasaan saudara tentang kejadian di peristiwa dalam cerita itu?

2. Pelajaran : Memberi diri untuk berubah

Ceritakanlah maksud dari memberi diri untuk berubah dan tuliskanlah kata kunci untuk menunjukkan perubahan tersebut pada secarik kertas kecil, dan tempelkan pada papan tulis di depan.

Apa saja perubahan yang terjadi setelah jemaat mula-mula memberi diri untuk diubah? Diskusikanlah dalam kelompok atau berpasangan dan bagikan pendapat di dalam kelompok. Satu dua orang membagikan pendapatnya.

\section{Penerapan:}

Disukusikan dalam kelompok, apa saja yang anda pikirkan, rasakan, dan lakukan apabila saudara sudah memberi diri untuk berubah. Tuliskan pada secarik kertas kecil, dan tempelkan itu pada papan tulis di depan.

4. Perubahan: Bertindak Sekarang

\footnotetext{
${ }^{25}$ Hengki Wijaya and Helaluddin Helaluddin, Analisis Data Kualitatif Sebuah Tinjauan Teori \& Praktik (Makassar: Sekolah Tinggi Theologia Jaffray Makassar, 2019).

${ }^{26}$ Hengki Wijaya and Arismunandar Arismunandar, "Pengembangan Model Pembelajaran Kooperatif Tipe STAD Berbasis Media Sosial," Jurnal Jaffray 16, no. 2 (October 6, 2018): 175-196.

${ }^{27}$ Roland Walker, "Learning That LASTS," n.d., https://wycliffe.fi/wpcontent/uploads/2018/12/intro-to-learning-that-lasts-walker.pdf.
} 
Diskusikanlah dalam kelompok untuk membuat drama singkat yang pesannya mirip dengan perubahan yang terjadi pada jemaat mula-mula dengan konteks pada masa kini. Masaing-masing kelompok memiliki kesempatan untuk menampilkan dramanya.

Tuliskanlah komitmen anda pada origami, apa yang akan anda lakukan untuk memberi diri untuk berubah seperti yang dilakukan oleh jemaat mula-mula, lipatlah kertas origami tersebut, dan sisipkan pada Alkitab anda pada bagian nas tersebut.

5. Penutupan

Berdoalah dengan pasangan anda untuk mendoakan komitmen yang telah ditulis di kertas origami.

\section{HASIL DAN PEMBAHASAN}

Dari proses pembelajaran yang penulis lakukan, maka tercantumlah hasil sebagai berikut:

1. Dalam tahapan penghubung responden dapat terlibat langsung dalam drama tentang Kisah Para Rasul 2:41-47. Teori belajar behavioristik merupakan teori belajar yang lebih mengutamakan pada perubahan tingkah laku siswa sebagai akibat adanya stimulus dan respon. ${ }^{28}$ Oleh sebab itu metode drama yang digunakan dalam penghubung berfungsi dengan baik, sehingga responden dalam kelas dapat membagikan apa yang mereka dapatkan setelah melihat drama tersebut.

2. Dalam tahap pelajaran, responden dapat membagikan peristiwa yang mereka alami berdasarkan cerita tersebut.

3. Dalam Penerapan, Kelompok dapat mendiskusikan apa saja yang anda pikirkan, rasakan, dan lakukan apabila saudara sudah memberi diri untuk berubah. Dan menuliskan pada secarik kertas kecil komitmen mereka.

4. Perubahan, pada tahap ini kelmpok dapat menghasilkan drma yang sesuai dengan kisah tersebut, dan mempraktekannya di dalam kelas.

5. Penutup, kelas menutup sesi pembelajaran dengan berdoa bersama untuk meneguhkan komitmen.

\section{KESIMPULAN}

Keselamatan merupakan hasil dari apa yang Yesus kerjakan, aspek keselamatan mencangkup banyak hal dan juga memiliki arti dalam cakupan hidupan manusia di masa depan. Namun sasaran utama dalam pembahasan jurnal ini, adalah membahas tanggapan manusia khususnya orang Kristen terhadap apa yang telah Allah buat baginya. Setiap orang yang menyerahkan dirinya bagi Yesus harus benar-benar meninggalkan kehidupan lamanya, atau di dalam istilah teologis mengalami pertobatan. Pertobatan merupakan langkah awal di dalam kekristenan setelah itu diikuti oleh iman dan pengampunan. Namun penulis menaruh perhatian khusus kepada langkah awal kehidupan Kristen, yaitu membawa orang ke dalam pengalaman kristiani.

Gaya hidup yang bertobat ini merupakan tindakan secara sadar bahwa perilaku di masa lalu adalah salah, dan ingin merubah itu menjadi perilaku yang serupa dengan karakter Kristus. Ini adalah sebua proses belajar bagi orang percaya yang terjadi secara terus-menerus di dalam kehidupannya. Proses pembelajaran ini sesuai jika ditinjau dari perspektif teori belajar Behavioristik, secara khusus teori yang dikembangkan oleh Ivan

${ }^{28}$ Nahar, "PENERAPAN TEORI BELAJAR BEHAVIORISTIK DALAM PROSES PEMBELAJARAN," 64. 
Petrovich Pavlov. Tujuan akhir dari pembelajaran ini adalah kesadaran otomatis akan gaya hidup bertobat, yang akhirnya menjadi suatu kebiasaan.

Kebiasaan hidup yang bertobat inilah yang akan menghasilkan dampak, yaitu perubahan-perubahan perilaku hidup yang secara otomatis akan terjadi dengan bantuan Roh Kudus seperti yang terjadi pada cara hidup jemaat mula-mula dalam Kisah Para Rasul 2:41-47. Gaya hidup bertobat harus diajarkan melalui pengajaran-pengajaran yang berdasarkan Alkitab sebagai inpuls, sehingga dapat menghasilkan output berupa respon, yaitu gaya hidup yang bertobat. Ini sesuai dengan teori belajar Behavioristik seperti yang dikembangkan oleh Ivan Pavlov.

\section{KEPUSTAKAAN}

Arifin, MUHAMMAD IMAM BUSTANUL. "PENGARUH PENERAPAN TEORI BELAJAR BEHAVIORISTIK DAN PRINSIP-PRINSIP PEMBELAJARAN TERHADAP MOTIVASI BELAJAR PESERTA DIDIK SMP AL-ISLAM GUNUNGPATI SEMARANG” (October 16, 2016): i-109.

Azhar, Dimas, Kadek Suranata, and I Ketut Darsana. "Implementation of The Behavioral Ivan Pavlov Conservation Theory with Modeling Techniques on Lesson Study Setting to Improve Self Achievement Students of The XI Class of Ibb SMA Lab Undiksha." Global Conferences Series: Sciences and Technology (GCSST) Volume 1 (2019): 156-159.

Deni Hardianto, Deni, and Hardianto. "PARADIGMA TEORI BEHAVIORISTIK DALAM PENGEMBANGAN MULTIMEDIA PEMBELAJARAN” (n.d.).

Familus. "TEORI BELAJAR ALIRAN BEHAVIORISTIK SERTA IMPLIKASINYA DALAM PEMBELAJARAN.” Jurnal PPKn \& Hukum Vol. 11. No. 2 (October 2016): 98-115.

Jayanthi, Karmila, Ketut Dharsana, and Dantes Nyoman. "Ivan Pavlov's Behavioral Counseling Effectiveness With Modeling Techniques to Improve Character Speaks Funnyly, Through Lesson Study." Global Conferences Series: Sciences and Technology (GCSST) Volume 1 (2019): 72-77.

Litalisdiana, Reia. "PENERAPAN TEORI BEHAVIORISME DALAM PENDIDIKAN DASAR KELAS II SDN PANGGANG” (n.d.).

Nahar, Novi Irwan. "PENERAPAN TEORI BELAJAR BEHAVIORISTIK DALAM PROSES PEMBELAJARAN." Nusantara ( Jurnal Ilmu Pengetahuan Sosial ) Volume 1 (December 2016): 64-74.

Nurhidayati, Titin. "IMPLEMENTASI TEORI BELAJAR IVAN PETROVICH PAVLOV (CLASSICAL CONDITIONING ) DALAM PENDIDIKAN." JURNAL FALASIFA Vol. 3. No. 1 (March 2012): 23-43.

Oktariska, Bariyah, and Anselmus J.E Toenlioe. "STUDI KASUS PENERAPAN TEORI BELAJAR BEHAVIORISTIK DALAM 
MENUMBUHKEMBANGKAN PERILAKU PEDULI LINGKUNGAN HIDUP SISWA DI SMKN 6 MALANG Bariyah Oktariska, Anselmus J.E Toenlioe, Susilaningsih.” JKTP Volume 1. Nomor 2 (June 2018): 159-168.

Seniasih, Ni Luh Linda, Suranata K, and Ketut Darsana. "Effectiveness Behavioral Counseling Ivan Pavlov Modeling Techniques on Lesson Study Setting to Improve Allied Characters." Global Conferences Series: Sciences and Technology (GCSST 1 (2019): 170-174.

Soesilo, Yushak. "Pentakostalisme Dan Aksi Sosial: Analisis Struktural Kisah Para Rasul 2:41-47." Jurnal Teologi dan Pendidikan Kristiani Volume 2. Nomor 2 (April 2018): 136-151.

Suherman, Ayi. "MODEL PEMBELAJARAN PAKEM DALAM PENDIDIKAN JASMANI DI SEKOLAH DASAR.” Jurnal Penelitian Pendidikan Vol. 11. No. 1 (April 2010): 131-141.

Sutoyo, Daniel. "Gaya Hidup Jemaat Mula-Mula Yang Disukai Berdasarkan Kisah Para Rasul 2:41-42 Bagi Gereja Masa Kini” (n.d.): 1-40.

Teja, I Komang Ribek Budiarta, Ketut Darsana, and K Sunarta. "Effectiveness of Behavioral Ivan Pavlov Conservation with Modeling Techniques to Increase Characters Helps Others Through Lesson Study." Global Conferences Series: Sciences and Technology (GCSST) Volume 1 (2019): 160-164.

Walker, Roland. "Learning That LASTS," n.d. https://wycliffe.fi/wpcontent/uploads/2018/12/intro-to-learning-that-lasts-walker.pdf.

Wijaya, Hengki, and Arismunandar Arismunandar. "Pengembangan Model Pembelajaran Kooperatif Tipe STAD Berbasis Media Sosial." Jurnal Jaffray 16, no. 2 (October 6, 2018): 175-196.

Wijaya, Hengki, and Helaluddin Helaluddin. Analisis Data Kualitatif Sebuah Tinjauan Teori \& Praktik. Makassar: Sekolah Tinggi Theologia Jaffray Makassar, 2019.

Zaluchu, Sonny Eli. "Eksegesis Kisah Para Rasul 2:42-47 Untuk Merumuskan Ciri Kehidupan Rohani Jemaat Mula-Mula Di Yerusalem.” Jurnal Teologi dan Pelayanan Kristiani Vol 2. No. 2 (November 2018): 72-82.

Zulhammi. "Teori Belajar Behavioristik Dan Humanistik Berdasarkan Perspekti f Pendidikan Islam.” Jurnal Darul Ilmi Vol. 3. No. 1 (January 2015): 105-127. 